\title{
Using inclusive wealth for policy evaluation: Application to electricity infrastructure planning in oil-exporting countries
}

\section{Citation}

Collins, Ross D., Noelle E. Selin, Olivier L. de Weck, and William C. Clark. 2017. “Using Inclusive Wealth for Policy Evaluation: Application to Electricity Infrastructure Planning in Oil-Exporting Countries." Ecological Economics 133 (March): 23-34. doi:10.1016/j.ecolecon.2016.11.013.

\section{Published Version}

10.1016/j.ecolecon.2016.11.013

\section{Permanent link}

http://nrs.harvard.edu/urn-3:HUL.InstRepos:32696191

\section{Terms of Use}

This article was downloaded from Harvard University's DASH repository, and is made available under the terms and conditions applicable to Open Access Policy Articles, as set forth at http:// nrs.harvard.edu/urn-3:HUL.InstRepos:dash.current.terms-of-use\#OAP

\section{Share Your Story}

The Harvard community has made this article openly available.

Please share how this access benefits you. Submit a story.

\section{Accessibility}




\section{Using I nclusive Wealth for Policy Evaluation: Application to Electricity I nfrastructure Planning in Oil- Exporting Countries Faculty Research Working Paper Series}

Ross D. Collins

Massachusetts Institute of Technology

Noelle E. Selin

Massachusetts Institute of Technology

Olivier L. de Weck

Massachusetts Institute of Technology

\section{William C. Clark}

Harvard Kennedy School

\section{March 2016}

\section{RWP16-010}

Visit the HKS Faculty Research Working Paper Series

at: https://research. hks. harvard.edu/publications/workingpapers/I ndex.aspx

The views expressed in the HKS Faculty Research Working Paper Series are those of the author(s) and do not necessarily reflect those of the J ohn F. Kennedy School of Government or of Harvard University. Faculty Research Working Papers have not undergone formal review and approval. Such papers are included in this series to elicit feedback and to encourage debate on important public policy challenges. Copyright belongs to the author(s). Papers may be downloaded for personal use only. 


\title{
Using inclusive wealth for policy evaluation: Application to electricity infrastructure planning in oil-exporting countries
}

\author{
Ross D. Collins ${ }^{1}$, Noelle E. Selin ${ }^{1,2}$, Olivier L. de Weck ${ }^{1,3}$, William C. Clark ${ }^{4}$
}

${ }^{1}$ Institute for Data, Systems, and Society, Massachusetts Institute of Technology, 77

Massachusetts Avenue, Cambridge, MA 02139, USA. Corresponding author. Email:

ross.collins8j@alum.mit.edu

${ }^{2}$ Department of Earth, Atmospheric and Planetary Sciences, Massachusetts Institute of

Technology, 77 Massachusetts Avenue, Cambridge, MA 02139, USA.

${ }^{3}$ Department of Aeronautics and Astronautics, Massachusetts Institute of Technology, 77

Massachusetts Avenue, Cambridge, MA 02139, USA.

${ }^{4}$ John F. Kennedy School of Government, Harvard University, 79 John F. Kennedy Street, Cambridge, MA 02138, USA. 


\begin{abstract}
Decision-makers often seek to design policies that support sustainable development. Prospective evaluations of how effectively such policies are likely to meet sustainability goals have nonetheless remained relatively challenging. Evaluating policies against sustainability goals can be facilitated through the inclusive wealth framework, which characterizes development in terms of the value to society of its underlying capital assets, and defines development to be potentially sustainable if that value does not decline over time. The inclusive wealth approach has been developed at a theoretical level and previously applied to retrospective evaluations. Here, we apply inclusive wealth theory to prospective policy evaluation coupled with dynamic simulation modeling, using a case of electricity infrastructure policies in oil-exporting countries. To demonstrate the prospective evaluation, we analyze investment policies in non-fossil electricity capacity in terms of their forecast impact on inclusive wealth. Illustrative results show that investing in non-fossil capacity in Saudi Arabia and Kuwait can increase the countries' inclusive wealth, though the impacts depend on future uncertainties. In contrast, the UAE's net inclusive wealth declines under similar investment policies. Finally, expanding the estimation of benefits to include human capital improvements can substantially increase net inclusive wealth, though calculated benefits vary across the countries.
\end{abstract}

Keywords: inclusive wealth; capital stocks; sustainable development; policy evaluation; simulation modeling; infrastructure 


\section{Introduction}

Decision-makers increasingly seek to design policies that support sustainable development (SDSN, 2014), or "meeting the needs of the present without compromising the ability of future generations to meet their own needs" (World Commission on Environment and Development, 1987). Achieving sustainable development requires both defining and measuring objectives, and designing and evaluating appropriate policies to achieve them. While much literature has focused on sustainability definitions and concepts, fewer studies have addressed the challenge of quantitative policy evaluation. Here, we demonstrate how a rigorous theoretical approach to defining sustainability based on the concept of "inclusive wealth" can be applied to prospective evaluation of policies, through a case study of electricity infrastructure investments in oilexporting countries.

The foundations of inclusive wealth lie in a substantial literature from economics. This includes early theoretical efforts on the sustainability implications of net national product or "net income" (Hicks, 1940; Lindahl, 1933) and the study of the evolution of the economy over time, that is, economic growth theory (e.g. Barro \& Sala-i-Martin, 2003). The foundations of inclusive wealth were recently reviewed by Dasgupta (2014) and Polasky et al. (2015). There have also been empirical attempts at wealth accounting using genuine savings (Hamilton \& Clemens, 1999; Lindmark \& Acar, 2013; Mota et al., 2010; Pearce \& Atkinson, 1993) and two contemporary streams of wealth accounting: comprehensive wealth (World Bank, 2006, 2011) and inclusive wealth (UNU-IHDP \& UNEP, 2012, 2014). While comprehensive and inclusive wealth approaches have some methodological differences, the underlying theory is consistent. Recent empirical attempts at regional inclusive wealth accounting include Ollivier \& Giraud (2011), Arrow et al. (2012), Moe et al. (2013), and Pearson et al. (2013). 
Inclusive wealth $W$ is defined as the social value of the capital asset stocks $\boldsymbol{K}$ in a society. It is an aggregate measure of a society's productive base, which tracks intergenerational human well-being (Dasgupta \& Duraiappah, 2012). The link to well-being requires that the assets $\boldsymbol{K}$ be valued per capita and at their social (also called shadow) prices $\boldsymbol{p}$, capturing externalities (Dasgupta, 2014). Inclusive wealth at time $t$ is shown below (Eq. 1) (ignoring the value of the passage of time).

$$
W(t)=\sum_{i} p_{i}(t) K_{i}(t)
$$

The capital assets $\boldsymbol{K}$ are, in principle, comprehensive, including all the stocks on which society draws to build its well-being. In practice, most treatments include familiar assets such as produced capital (also called reproducible or manufactured capital, including durable items such as infrastructure, buildings, and machinery), human capital (the experience, education, and skills of the population), and natural capital (renewable assets like forests and fisheries and nonrenewable assets like fossil fuels and minerals). Additional categories of capital included in the framework but not yet evaluated in most empirical studies are intangible assets like social capital (which may include institutional, cultural and/or religious capital) and knowledge capital.

Inclusive wealth theory states that development is sustainable if inclusive wealth per capita does not decline over time (Arrow et al., 2012; Dasgupta, 2009, 2014). By focusing on changes to capital stocks, inclusive wealth measures changes to the capacity of nations to provide future flows of goods and services to its citizens from its productive base (Dasgupta, 2009; Meadows, 1998). It therefore tracks changes in "the ability of future generations to meet their own needs" (intergenerational human well-being), whereas measures of yearly flows do not 
(Arrow et al., 2012). Applied to policy evaluation, the theory states that a policy meets the acceptance criteria if it would increase or at least maintain inclusive wealth (Arrow et al., 2003; Dasgupta, 2009).

Applications of wealth accounting theory have to date focused almost exclusively on retrospective accounting of past performance. A few studies have forecast inclusive wealth (Sato et al., 2012; Tokimatsu et al., 2011, 2013), but do not use inclusive wealth to compare alternative policies. Pearson et al. (2013) and Collins et al. (2014) describe frameworks for applying inclusive wealth theory to prospective policy evaluation, namely assessing the potential impact of a policy on the future trajectory of inclusive wealth, but their policy applications were merely illustrative.

Here, we demonstrate how inclusive wealth theory can be used for prospective and quantitative policy evaluation. We apply this approach to a case of electricity infrastructure planning in oil-exporting countries, for which we are able to capture important dynamics using a limited number of capital assets. To estimate the accumulations (benefits) and depletions (costs) of capital stocks caused by different policy choices for infrastructure development, we develop a dynamic simulation model of energy-economy interactions for oil-exporting countries, using Saudi Arabia as the primary case study. We then use the model to evaluate net impacts to inclusive wealth of different non-fossil investment plans under a range of scenarios and across a sample of other oil-exporting countries. Finally, we discuss perspectives and challenges related to the implementation of inclusive wealth-based policy evaluation for sustainable development. 


\section{Methods}

Section 2.1 describes the dynamic simulation model we develop to evaluate electricity policies in terms of their effect on the capital assets of inclusive wealth theory. Section 2.2 defines how policies are implemented in the simulation model and the data employed to conduct simulations. Section 2.3 evaluates policies as a social cost-benefit analysis in which a policy is sustainable if the present discounted value of its social profits is positive; equivalently, its net present value is greater than zero. This occurs when benefits (measured as the social value of its capital accumulations) exceed costs (measured as the social value of its capital depletions). In Section 3, we use this formulation to measure produced and human capital benefits relative to oil capital costs across a range of policies.

\subsection{Model Description}

We develop and use a dynamic simulation model (Figure 1) that captures the interaction between two processes, electric power capacity expansion and macroeconomic development, and subsequent impacts to produced, human, and natural (specifically oil) capital. Inputs are parameters and time series of the electricity and economic systems, and outputs are timedependent values of the capital stocks. In the model, population and GDP growth increases electricity demand. This leads to the expansion of electric power capacity to meet the demand, which has associated infrastructure (fixed and variable) costs. These costs are financed through oil capital depletion. Depending on the technology composition of the electricity infrastructure conventional (oil- and natural gas-fired) versus non-fossil - a certain amount of natural (oil) capital will be consumed. Lower domestic consumption leads to more oil exports, all else being equal, which increases GDP and the accumulation of produced and human capital. The oil price is treated as an exogenous variable. 


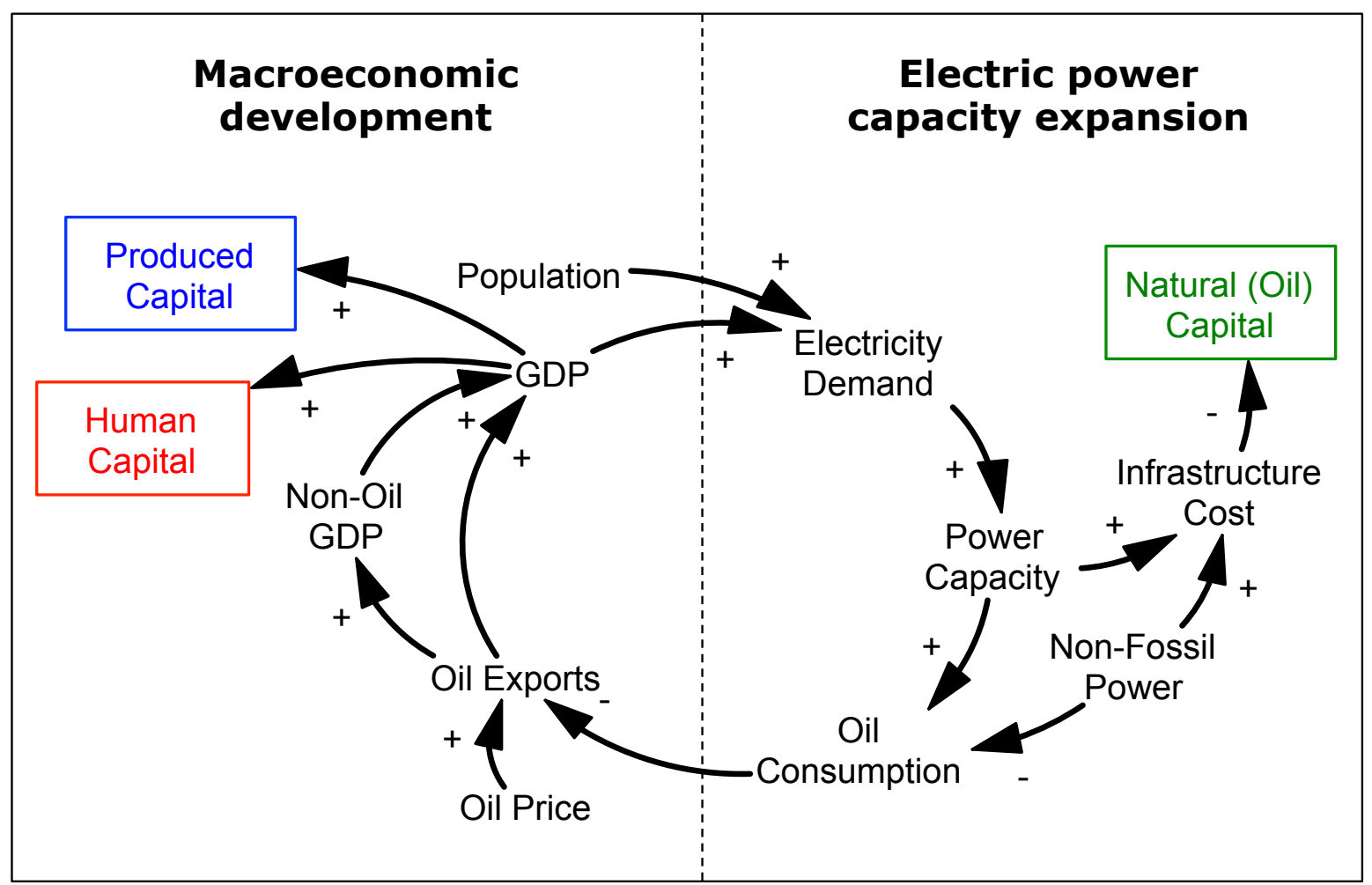

Figure 1: Overview of dynamic simulation model. Plus or minus at the arrow head indicates the polarity of the causal relationship. Boxes represent stocks.

\subsubsection{Electric power capacity expansion (right hand side of Fig. 1)}

We quantify electricity demand as a function of population and real GDP using multiple linear regression, an approach consistent with literature on electricity and energy demand forecasting (Bianco et al., 2009; Kypreos et al., 2003; Mohamed \& Bodger, 2005). We use log-log regression to capture the effect of the two drivers on electricity demand (Eq. 2). Electricity demand $(E)$, population $(P)$ and real GDP $(Y)$ are all represented as relative terms, with the initial simulation year values (time $t=0$ ) in the denominator. The $\beta_{i}$ coefficients are the electricity demand elasticities of population and real GDP, estimated using World Bank (2014) data.

$$
\log \left(\frac{E_{t}}{E_{t=0}}\right)=\beta_{0}+\beta_{1} \log \left(\frac{P_{t}}{P_{t=0}}\right)+\beta_{2} \log \left(\frac{Y_{t}}{Y_{t=0}}\right)+\epsilon
$$


Electricity infrastructure expansion is simulated using the well-established control structure from the system dynamics literature (Sterman, 2000), previously applied in numerous models of generation capacity expansion and investment (Ford, 1997; Dyner \& Larsen, 2001; Ford, 2002; Collins et al., 2013; Gowharji et al., 2014). Briefly, capacity expands to meet a forecast of electricity demand (also called load). System size depends on peak load (the largest instantaneous demand for power over the year) and reserve margin (the percentage buffer of capacity in excess of peak load). The expansion rate depends on adjustment times for capacity online and under construction. Equations and parameters can be found in the appendix.

Without non-fossil power, demand in the model is met solely with conventional (oil and natural gas) capacity. The amount of oil consumed (Oil) by the electricity infrastructure (Eq. 3) depends on three things: (1) the fraction of power generated by natural gas $\left(f_{g}\right) ;(2)$ total conventional power generation, which is the product of conventional capacity (Cap) and its capacity factor $(\mathrm{CF})$; and (3) the average heat rate $(H R)$ of the oil-fired generation plants, where higher $H R$ indicates lower efficiency ( $b$ is the energy content of a barrel of oil). As non-fossil capacity comes online and starts generating power $\left(G_{N F}\right)$, the capacity factor (i.e. utilization) of the conventional system declines, which decreases oil consumption (Eq. 4).

$$
\begin{gathered}
O i l_{t}=\left(1-f_{g}\right)\left[\operatorname{Cap}_{t} * C F_{t} * 8760\right]\left(\frac{H R_{t}}{b}\right) \\
C F_{t}=\operatorname{Min}\left(1, \frac{E_{t}-G_{N F, t}}{\operatorname{Cap}_{t} * 8760}\right)
\end{gathered}
$$


We calculate the cost of the electricity infrastructure as it evolves over time to meet electricity demand. These include fixed (capital plus fixed operation and maintenance (O\&M)) and variable (fuel cost plus variable O\&M) costs. Capital and O\&M costs are technologyspecific (see Table 2). The capital cost $(C)$ is an overnight cost, the cost incurred during construction if the plant were completed "overnight". To account for borrowed money to finance construction, we spread the cost evenly over the lifetime $(n)$ of the power plant using the weighted average cost of capital (WACC) and a capital recovery factor $(C R F)$ to get an annualized capital payment (c) for technology $i$ (Eq. 5). Furthermore, base overnight capital costs $\left(C_{\text {base }}\right)$ are adjusted to include the cost of financing during construction, which assumes that the capital costs are divided evenly over each year of construction and interest accrues at the WACC (Eq. 6). We use a WACC of $10 \%$.

$$
\begin{gathered}
c_{i}=C_{a d j, i} C R F_{i}=C_{a d j, i}\left[\frac{W A C C}{\left(1-\left(\frac{1}{(1+W A C C)^{n_{i}}}\right)\right)}\right] \\
C_{a d j}=\frac{C_{\text {base }}}{\tau_{d}} \sum_{t=1}^{\tau_{d}}(1+W A C C)^{t}
\end{gathered}
$$

We assume that the electricity infrastructure deployment cost is $100 \%$ financed by oil capital $(O C)$ depletion, that is, the extraction and sale of oil at international market prices. Following Arrow et al. (2012), oil capital is the product of the stock, the market price, and the rental rate (Eq. 7). For natural resources, the rental rate is the difference between unit price and extraction cost, divided by the extraction cost. The product of the market price and the rental rate 
is the rental price, which is used as a proxy for the shadow price. The oil stock declines according to a yearly exogenous production rate, plus an additional amount $X_{t}$ that is needed to finance the infrastructure (Eq. 8).

$$
\begin{aligned}
& \text { OC }(t)=\text { Stock }_{t} \times \text { Price }_{t} \times \text { Rental_Rate }_{t} \\
& \text { Stock }_{t}=\text { Stock }_{t-1}-\text { Production }_{t}-X_{t}
\end{aligned}
$$

\subsubsection{Macroeconomic development (left hand side of Fig. 1)}

Domestic oil consumption is the sum of electricity and non-electricity consumption, the latter assumed exogenous and based on data from Lahn et al. (2013) and US Energy Information Administration (2014b). Oil exports are the difference between oil production (assumed exogenous) and domestic consumption. The product of oil exports with the international oil price (assumed exogenous) gives oil export revenues.

We partition the economy of oil-exporting countries into two sectors: oil and non-oil. Oil sector GDP $\left(Y_{o i l}\right)$ is equivalent to oil export revenue, and non-oil GDP $\left(Y_{\text {non-oil }}\right)$ includes all other economic activity (including non-oil exports and the domestic production of non-oil sectors).

The Saudi Arabian Monetary Agency (SAMA) and other central banks in oil-exporting countries use this partitioning to tabulate national statistics. Total GDP $Y(t)$ in year $t$ is the sum of $Y_{\text {oil }}(t)$ and $Y_{\text {non-oil }}(t) . Y(t)$ is converted to real dollars using year 2000 deflators (World Bank, 2014).

As domestic oil consumption grows, there are direct and indirect economic impacts in the model. Increased consumption leads directly to less oil leftover for export, which decreases oil GDP, all else being equal. The indirect impact stems from the dependency of the non-oil sector 
on the oil sector. Oil revenues are frequently an oil-exporting government's primary means for financing investments in non-oil sectors, including physical projects (e.g. highways, real estate) and social programs (e.g. schools, hospitals), as well as paying government employees (Bourland \& Gamble, 2011). As a result, income and spending have tended to increase (decrease) during times of high (low) oil prices (Alsweilem, 2015; Pierru \& Matar, 2012). Table 1 displays oil revenue as a percentage of export earnings, state budget and overall GDP in several oil-exporting countries.

Table 1: Oil revenue as a percentage of economic indicators in Gulf Cooperation Council (GCC) countries (Hvidt, 2013).

\begin{tabular}{|l|c|c|c|}
\hline Country & \% of export earnings & \% of state budget & \% of GDP \\
\hline Bahrain & 69 & 86 & 24 \\
\hline Kuwait & 90 & 93 & 45 \\
\hline Oman & 65 & 77 & 41 \\
\hline Qatar & 91 & 80 & 46 \\
\hline Saudi Arabia & 85 & 85 & 50 \\
\hline United Arab Emirates & 69 & 77 & 32 \\
\hline
\end{tabular}

To capture the indirect impact, we assume a linear effect of the oil sector $\left(Y_{\text {oil }}\right)$ on the non-oil sector $\left(Y_{\text {non-oil }}\right)$, as well as an exogenous growth rate $\gamma$ of $Y_{\text {non-oil }}$ that is independent of $Y_{\text {oil }}$ (Eq. 7). The linear effect is dampened by a parameter $\tau>1$ that governs how linked $Y_{\text {non-oil }}$ is to $Y_{\text {oil }}$. The higher the value of $\tau$, the more quickly changes to $Y_{\text {oil }}$ will be reflected in changes to $Y_{\text {non-oil. }}$ The parameters $\alpha$ and $\beta$ are estimated using SAMA (2013) and World Trade Organization (2015) data. We do not estimate $\tau$ and $\gamma$ from data, but instead vary their values in a sensitivity analysis to discern the impact on policy evaluation results.

$$
\frac{d Y_{\text {non-oil }}(t)}{d t}=\frac{\left[a Y_{\text {oil }}(t)+\beta\right]-Y_{\text {non-oil }}(t)}{\tau}+\gamma Y_{\text {non-oil }}(t)
$$


We specify the dynamics of produced and human capital based on the formulations and parameter assumptions of Arrow et al. (2012). Produced capital (PC) accumulation is equivalent to net national savings, namely output $Y(t)$ net of consumption and depreciation (Eq. 8).

However, we alter the formulation slightly so that consumption $c$ is a fixed fraction of output. The depreciation rate $\lambda$ is $7 \%$, and the consumption fraction $c$ is an historical average calculated from UNSD (2013) data. Initial stock values are from Inclusive Wealth Report (IWR) data annexes (UNU-IHDP \& UNEP, 2012, 2014).

$$
\frac{d P C(t)}{d t}=Y(t)(1-c)-\lambda P C(t)
$$

Human capital $(H C)$ is the product of three terms (Eq. 11). The first term represents the amount of human capital per adult, a function of average educational attainment $A$ and the market return on education $\rho(8.5 \%)$. Educational attainment figures are from the Barro \& Lee (2013) dataset. The second term is the size of the population over the age of 15, a proxy for the adult population. To calculate adult population, we multiply the historical average adult population percentage $p_{a}$ by total population $P$ (Eq. 12). The third term is the shadow price of human capital, namely the discounted labor compensation over the remaining working period $T$ (14 years) of an average adult (Muñoz, 2013), discounted at a rate $\delta(8.5 \%)$. Assuming a sufficiently competitive labor market, the marginal productivity of human capital is equivalent to the rental price for a unit of human capital, $r$. This rental price is the real wage for human capital, calculated as the total wage bill divided by the number of employed people (Arrow et al., 2012) (Eq. 11). Total wage bill data is not readily available for the countries of interest in this paper. Thus, using US wage bill data (BEA, 2015), we calculate the ratio of the wage bill to US real 
GDP (54\%), and apply the this fraction to real GDP in order to calculate the wage bill. The number of employed human capital units is the product of the historical average employed population percentage $p_{e}$, total population, and human capital per adult.

$$
\begin{gathered}
H C(t)=e^{\rho A(t)} \times P_{15+}(t) \times \int_{t}^{t+T} r(t) e^{-\delta t} d t \\
P_{15+}(t)=p_{a} P(t) \\
r(t)=\frac{0.54 Y(t)}{p_{e} P(t) e^{\rho A(t)}}
\end{gathered}
$$

In summary, electricity infrastructure affects produced and human capital accumulation through its oil consumption. Reducing oil consumption leads to more oil exports and higher GDP in both the oil and non-oil sector. This has a direct positive effect on produced capital, and a positive effect on human capital via increase to the real wage. Furthermore, the generation technologies that comprise the infrastructure have different fixed and variable costs. The costs of alternative electricity policies will be reflected in how much oil capital needs to be liquidated to finance investment and operation of non-fossil based infrastructure.

\subsection{Model Parameterization}

Tables 2-3 show the parameterizations of the model. All historical averages are based on data going back to 2000 unless stated otherwise. Table 2 includes the cost and performance attributes of the electricity generation technologies. Table 3 displays country-specific parameters for three 
oil-exporting countries: Kingdom of Saudi Arabia (KSA), United Arab Emirates (UAE), and Kuwait. Initial values are for the year 2000.

The UAE and Kuwait were chosen for comparison for several reasons. One, oil represents a similar percentage contribution to the countries' export earnings, government budget, and overall GDP (see Table 1). Two, they provide a spectrum of population sizes. The 2013 populations of KSA, UAE and Kuwait were 28.83, 9.35 and 3.37 million people, respectively. Finally, there is variability in electricity and economic parameters across the countries (see Table 3). For instance, while all three have electricity systems that run solely on oil and natural gas, the percentage contribution of oil is different. The UAE uses mostly natural gas, Kuwait mostly oil, and Saudi Arabia roughly an even proportion. In short, the UAE and Kuwait have similar structures to their economies and electricity systems, yet their parameters differ.

Table 2: Cost and performance parameters for electricity technologies. Sources: ECRA (2006) [1], EIA (2014a) [2], Matar et al. (2014) [3], Tidball et al. (2010) [4].

\begin{tabular}{|l|l|l|l|l|}
\hline Parameter & Conventional & Nuclear & Solar PV & Source \\
\hline $\begin{array}{l}\text { Adjusted overnight } \\
\text { capital cost, } C_{a d j}(\$ / \mathrm{kW})\end{array}$ & 2,000 & 6,732 & 2,365 & {$[2,3]$} \\
\hline $\begin{array}{l}\text { Fixed O\&M cost }(\$ / \mathrm{kW}- \\
\text { year) }\end{array}$ & 11.5 & 100.0 & 30.0 & {$[2,3]$} \\
\hline $\begin{array}{l}\text { Variable O\&M cost } \\
(\$ / \mathrm{MWh})\end{array}$ & 3.00 & 2.14 & 0.00 & {$[2,3]$} \\
\hline $\begin{array}{l}\text { Fuel cost, subsidized } \\
\text { (\$/MMBtu) }\end{array}$ & $\begin{array}{l}\text { Oil: } 0.60 \\
\text { Natural gas: } 0.75\end{array}$ & 0.43 & 0.00 & {$[2,3]$} \\
\hline Plant lifetime, $n$ (years) & 30 & 40 & 25 & {$[1,4]$} \\
\hline $\begin{array}{l}\text { Construction delay, } \tau_{d} \\
\text { (years) }\end{array}$ & 3 & 6 & 2 & {$[2]$} \\
\hline $\begin{array}{l}\text { Capacity factor, } C F \\
(\text { Dmnl) }\end{array}$ & $\begin{array}{l}\text { Endogenous, see } \\
\text { Eq. }(4)\end{array}$ & 0.9 & 0.2 & {$[4]$} \\
\hline $\begin{array}{l}\text { Average heat rate } \\
(\text { Btu/kWh) }\end{array}$ & 10,000 & 10,464 & N/A & {$[3,4]$} \\
\hline
\end{tabular}


Table 3: Economic and electricity system parameters for oil-exporting countries. Sources: Barro \& Lee (2013) [1], ECRA (2012b) [2], EIA (2014b) [3], IEA (2014) [4], SAMA (2013) [5], TCB (2013) [6], UNSD (2013) [7], UNU-IHDP (2014) [8], World Bank (2014) [9], WTO (2015) [10].

\begin{tabular}{|c|c|c|c|c|}
\hline Parameter & KSA & UAE & Kuwait & Source \\
\hline Initial population, $P_{t=0}$ & $20,144,600$ & $3,026,352$ & $1,906,231$ & [9] \\
\hline $\begin{array}{l}\text { Initial real GDP, } Y_{t=0} \\
\text { (2000 US } \$ \text { ) }\end{array}$ & $1.9 \mathrm{e} 11$ & $1.0 \mathrm{e} 11$ & $3.8 \mathrm{e} 10$ & [9] \\
\hline $\begin{array}{l}\text { Initial non-oil GDP } \\
\text { (US\$) }\end{array}$ & $1.1 \mathrm{e} 11$ & $7.6 \mathrm{e} 10$ & $2.0 \mathrm{e} 10$ & {$[5,10]$} \\
\hline $\begin{array}{l}\text { Initial produced capital } \\
\text { (2000 US\$) }\end{array}$ & $3.3 \mathrm{e} 11$ & $2.7 \mathrm{e} 11$ & $4.5 \mathrm{e} 10$ & [8] \\
\hline $\begin{array}{l}\text { Initial electricity } \\
\text { demand, } E_{t=0}(\mathrm{kWh})\end{array}$ & $1.3 \mathrm{e} 11$ & $4.0 \mathrm{e} 10$ & $3.2 \mathrm{e} 10$ & [9] \\
\hline Initial capacity $(\mathrm{GW})$ & 25.8 & 13.0 & 6.9 & {$[2,3]$} \\
\hline $\begin{array}{l}\text { Fraction of power from } \\
\text { natural gas, } f_{g}(\mathrm{Dmnl})\end{array}$ & 0.5 & 0.96 & 0.3 & [4] \\
\hline$\beta_{1}$ from Eq. (2) & 0.66 & 0.60 & 0.82 & [9] \\
\hline$\beta_{2}$ from Eq. (2) & 0.72 & 0.55 & 0.30 & [9] \\
\hline$\alpha$ from Eq. (9) & 0.79 & 1.69 & 0.44 & {$[5,10]$} \\
\hline$\beta$ from Eq. (9) & $5.7 \mathrm{e} 10$ & $4.9 \mathrm{e} 10$ & $2.1 \mathrm{e} 10$ & {$[5,10]$} \\
\hline$\gamma$ from Eq. $(9)^{(\dagger)}$ & 0.1 & 0.1 & 0.1 & {$[5,10]$} \\
\hline$\tau$ from Eq. (9) ${ }^{(\$)}$ & 20 & 20 & 20 & \\
\hline $\begin{array}{l}\text { Consumption fraction, } c \\
\text { (Dmnl) }\end{array}$ & 0.81 & 0.77 & 0.83 & [7] \\
\hline Adult population $\%, p_{a}$ & 0.64 & 0.71 & 0.84 & [1] \\
\hline $\begin{array}{l}\text { Employed population } \% \text {, } \\
p_{e}\end{array}$ & 0.33 & 0.59 & 0.94 & [6] \\
\hline
\end{tabular}

$\dagger$ Based on average historical growth rate in nominal non-oil GDP across the countries

† Chosen arbitrarily but varied in policy evaluation to discern impact

Exogenous time series inputs to the model are driven by historical data and projected trends. For population, we use the medium fertility projection for each country from UNDESA (2014). For educational attainment, we linearly extrapolate to 2050 attainment achieved between 1990 and 2010 in each country. For oil production, we use the 2024 forecasts from Business Monitor International extrapolated to 2050 (BMI, 2014, 2015a, 2015b). Non-electricity oil consumption in each country is assumed to grow at its historical rate. Finally, we assume a long- 
term oil price trajectory that is flat at $\$ 100$ per barrel, but we assess additional oil price scenarios in Section 3.1.

\subsection{Model Validation}

Based on the model structure and parameterization detailed in the previous sections, we evaluate the model's ability to replicate historical behavior. Figure 2 shows actual and simulated time series in Saudi Arabia from 2000 to 2013 for four of the key variables in the model: electricity demand, conventional capacity, oil consumption, and non-oil GDP. The mean absolute percentage error (MAPE) for the four time series are 4\%, 2\%, 2\%, and 5\%, respectively. These four variables are calculated endogenously within the model. While the model is not intended to make predictions, the simulated fit to historical data nonetheless provides justification for the modeling assumptions above. 

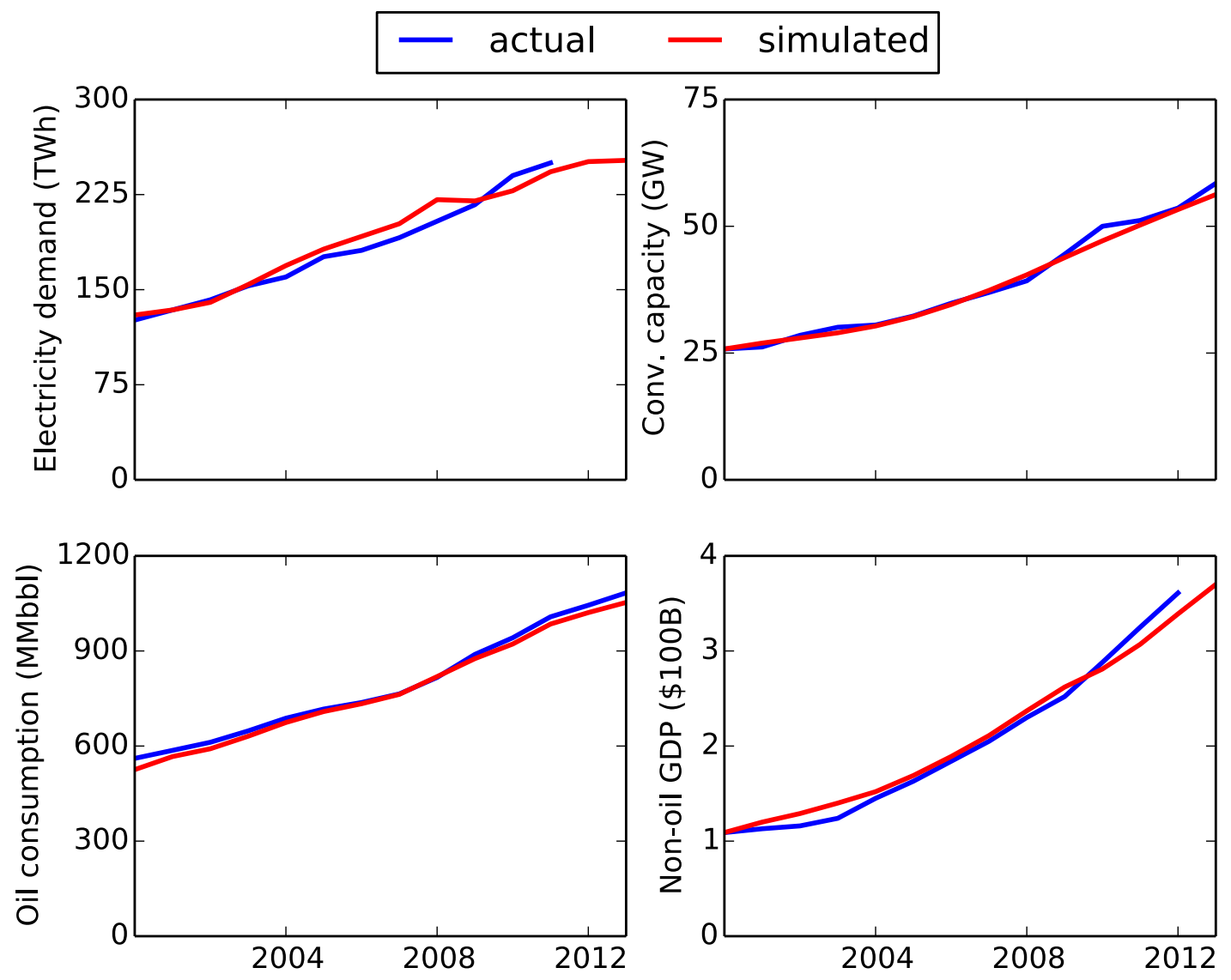

Figure 2: Actual and simulated time series for electricity demand, conventional capacity, domestic oil consumption, and non-oil GDP in Saudi Arabia from 2000 to 2013.

The MAPE values for UAE and Kuwait were not as low, largely because historical GDP in the two smaller countries was more volatile, particularly around the financial crisis of 2008 . Non-oil GDP was the time series with the largest MAPE value, at $12 \%$ and $17 \%$ in the UAE and Kuwait, respectively. Overall, however, these figures show that a simple, general structure of energy-economy interactions in oil-exporting countries can be applied across different countries.

For full details on model validation, including error component analysis using Theil statistics, refer to Collins (2015). 


\subsection{Policy Definition and Evaluation}

We use the model to simulate the impact of alternative electricity policies on the dynamics of produced, human, and oil capital. We define an alternative policy as a target penetration $\theta(0<\theta$ $\leq 1)$ of non-fossil power capacity in the electricity system by the terminal year of the simulation. Under the business-as-usual (BAU) policy, demand is met solely with conventional capacity fueled by oil and natural gas (i.e. $\theta=0$ ). Non-fossil capacity consists of nuclear and/or solar photovoltaic capacity, determined by fractional allocations $f_{N}$ and $f_{S}$, respectively, where $f_{N}+f_{S}=$ 1. The rate at which each technology comes online depends on the amount of capacity desired and the construction delay time. Simulations run from year 2000 to 2050. Equations can be found in the appendix.

To evaluate net changes to inclusive wealth, we employ a standard social cost-benefit analysis (CBA), using the capital asset stocks as the terms in which social costs and benefits are tabulated. Specifically, following Dasgupta $(2001,2009)$, policy benefits and costs are measured as the social value of capital accumulations and depletions, respectively. The benefits and costs of non-fossil electricity policies are evaluated relative to the BAU capacity expansion policy $(\theta=$ 0). Policies begin to be implemented in the year 2015 (i.e. when nuclear and/or solar capacity enters the construction pipeline), and all benefits and costs are discounted (at rate $\delta$ ) to 2015 through a present value calculation.

The benefits relative to the BAU manifest in terms of accrued produced capital $(P C)$ and human capital $(H C)$. The costs relative to the BAU are the fixed and variable costs necessary to finance the new infrastructures, and these costs are $100 \%$ financed by oil capital $(O C)$ depletion. Non-fossil electricity policies will perturb the produced and human capital trajectories upward (creating a wedge of benefits) and the oil capital trajectory downward (creating a wedge of 
costs). Alternative policies are evaluated using net present value (NPV), which calculates the difference between the present value of benefits and costs. If present value benefits exceed present value costs (i.e. NPV >0), then the policy meets the acceptance criteria since social profits are positive (Arrow et al., 2003; Dasgupta, 2009). All present value calculations are in year 2000 US dollars. The equations for NPV (Eq. 14) and the present value (PV) of produced, human, and oil capital (Eqs. 15, 16, 17) are shown below.

$$
\begin{gathered}
N P V_{\theta=i}=\left[P V\left(\Delta P C_{\theta=i}\right)+P V\left(\Delta H C_{\theta=i}\right)\right]-P V\left(\Delta O C_{\theta=i}\right) \\
P V\left(\Delta P C_{\theta=i}\right)=\sum_{t=2015}^{2050} \frac{P C_{\theta=i, t}-P C_{\theta=0, t}}{(1+\delta)^{t}} \\
P V\left(\Delta H C_{\theta=i}\right)=\sum_{t=2015}^{2050} \frac{H C_{\theta=i, t}-H C_{\theta=0, t}}{(1+\delta)^{t}} \\
P V\left(\Delta O C_{\theta=i}\right)=\sum_{t=2015}^{2050} \frac{O C_{\theta=i, t}-O C_{\theta=0, t}}{(1+\delta)^{t}}
\end{gathered}
$$

\subsection{Policy Cases}

We conduct the policy evaluation for four different policy cases: BASE, TECH, COST, and ECON. In each case, we are evaluating 100 different policies (i.e. $\theta=0.01,0.02, \ldots, 1.0)$ relative to the BAU (i.e. $\theta=0$ ), but the overall circumstances are different. The BASE case sets equal allocations to nuclear and solar capacity $\left(f_{N}=f_{S}=0.5\right)$ and uses the parameter values from Tables 2 and 3. The TECH case analyzes four different allocations to nuclear and solar capacity, 
specifically where nuclear comprises $0 \%, 33 \%, 67 \%$, and $100 \%$ of non-fossil capacity (the rest being solar).

The purpose of the COST and ECON cases is to assess the robustness of non-fossil electricity policies to future uncertainties. In the COST case, we analyze the BASE case under two different scenarios of the oil price trajectory and two scenarios of higher/lower nuclear and solar investment costs. The first oil price scenario decreases at 2\%/year from $\$ 100$ starting in 2014 , reaching $\$ 47$ per barrel by 2050 . The second scenario has a post-2014 oil price that is flat at $\$ 30$, in other words if current prices were to continue into the future. These alternative trajectories do not include short-term volatility in the oil price, and they are not meant to be predictions. For investment costs, the two scenarios have overnight capital costs $\left(C_{a d j}\right)$ for nuclear and solar being 20\% higher and lower than their Table 2 values.

In the ECON case, we analyze BASE case policies under four different scenarios with higher/lower values to the two parameters that control development of the non-oil sector, $\tau$ and $\gamma$. Specifically, we vary the two parameters independently at $+/-50 \%$ of their Table 3 values.

\section{Results}

Section 3.1 presents results for Saudi Arabia for the four policy cases. Benefits include only produced capital accumulations (human capital is omitted). Section 3.2 compares BASE case results for Saudi Arabia with two other oil-exporting countries, the UAE and Kuwait. Section 3.3 makes the same comparison, but with human capital accumulations included in the analysis.

\subsection{Results for Saudi Arabia}

Figure 3a shows the present value (PV) benefit (social value of produced capital accumulation) and cost (social value of oil capital depletion) curves for the BASE case (equivalent nuclear and 
solar allocations). The slopes of the PV benefit and cost curves are the marginal benefits and costs of a unit increase to $\theta$. Figure $3 \mathrm{~b}$ shows the NPV curve across the range of $\theta$. Here, NPV is simply the difference between produced capital benefits (the blue curve) and oil capital costs (the green curve), relative to the BAU. The acceptance criterion $-\mathrm{NPV}>0$ - is met across the entire range of $\theta$. In short, any non-fossil electricity policy in Saudi Arabia with equivalent allocations of nuclear and solar meets the policy acceptance criteria using inclusive wealth analysis.
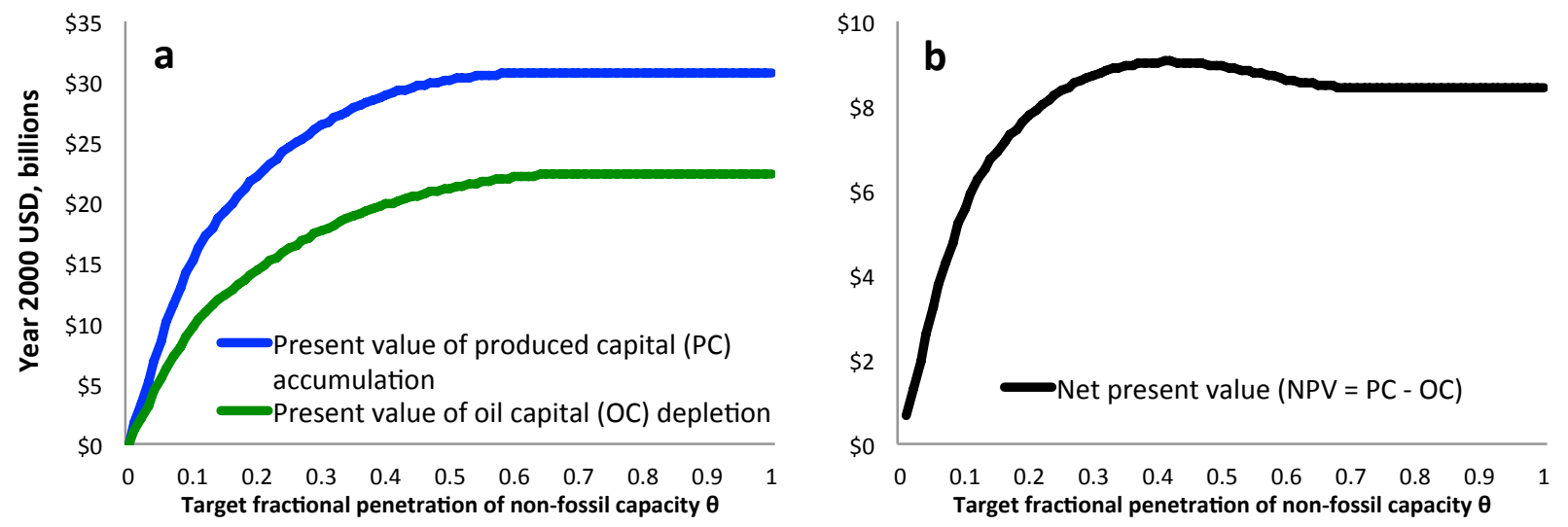

Figure 3a: Present value benefit (produced capital accumulation) and cost (oil capital depletion) curves for the BASE case in Saudi Arabia. Figure 3b: Net present value (NPV) curve for the BASE case in Saudi Arabia. Under the BASE case, nuclear and solar are equally allocated $\left(f_{N}=f_{S}=0.5\right)$.

Figure 4 shows NPV curves for the TECH case, where there are four different percentage allocations to nuclear $\left(f_{N}\right)$ and solar $\left(f_{S}\right)$ capacity. As modeled, a $100 \%$ nuclear system $\left(f_{N}=1, f_{S}\right.$ $=0$ ) will yield the greatest net benefits across the entire range of $\theta$. The significantly larger benefits of nuclear stem from its high capacity factor $(C F)$ relative to solar (0.9 versus 0.2$)$. At this higher capacity factor, nuclear displaces much more oil from electricity generation per unit of capacity. While each unit of capacity costs roughly three times more than solar $(\$ 6,732$ per $\mathrm{kW}$ versus $\$ 2,365$ per $\mathrm{kW}$ ), leading to more oil capital depletion to finance the infrastructure, the benefits via real GDP and produced capital accumulation significantly outweigh these costs. Nevertheless, all of the allocations in Figure 4 , including the $100 \%$ solar system $\left(f_{N}=0, f_{S}=1\right)$, 
result in NPV $>0$ across the range of $\theta$. Thus, all of the non-fossil electricity policies meet the policy acceptance criteria using inclusive wealth analysis.

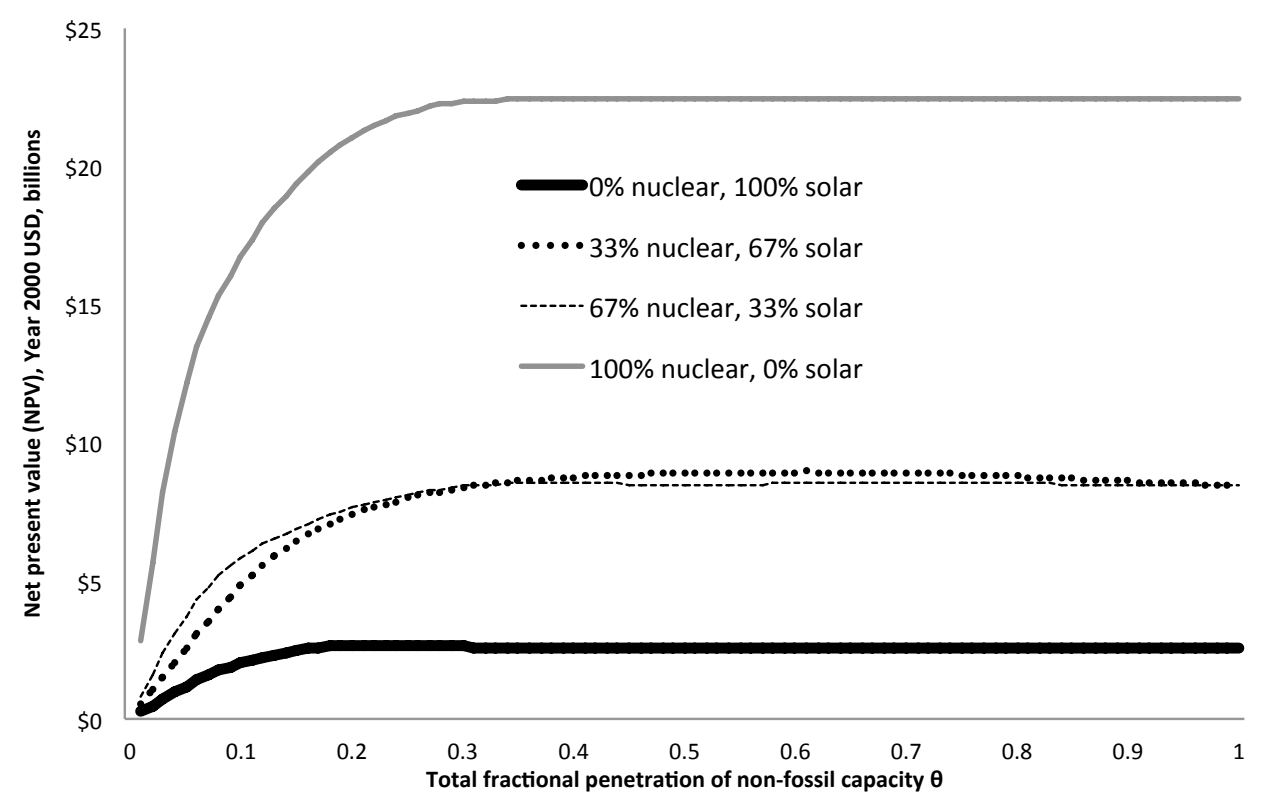

Figure 4: Net present value (NPV) curves for the TECH case in Saudi Arabia. Under the TECH case, nuclear and solar are allocated in four different combinations.

Figure 5 shows the NPV curves for the four scenarios of the COST case. In a world of lower oil prices, each barrel displaced from the electricity system is less valuable to the economy, leading to less produced capital accumulation. As a result, these scenarios shift the NPV curves downward. Specifically, if the oil price decreases at $2 \% /$ year from $\$ 100$, then NPV $<0$ on the interval $0.5<\theta \leq 1.0$; if it remains at $\$ 30$ per barrel on average to 2050 , then NPV $<0$ across the entire range of $\theta$. Under these conditions, non-fossil electricity policies do not meet the policy acceptance criteria using inclusive wealth analysis. If investment costs for nuclear and solar are less (more) expensive per unit of capacity, then less (more) oil capital is needed to finance development. As a result, the NPV curve is shifted upward (downward). However, even with investment costs $20 \%$ higher than expected, non-fossil capacity expansion still meets the acceptance criteria (NPV $>0$ ) across the range of $\theta$. 


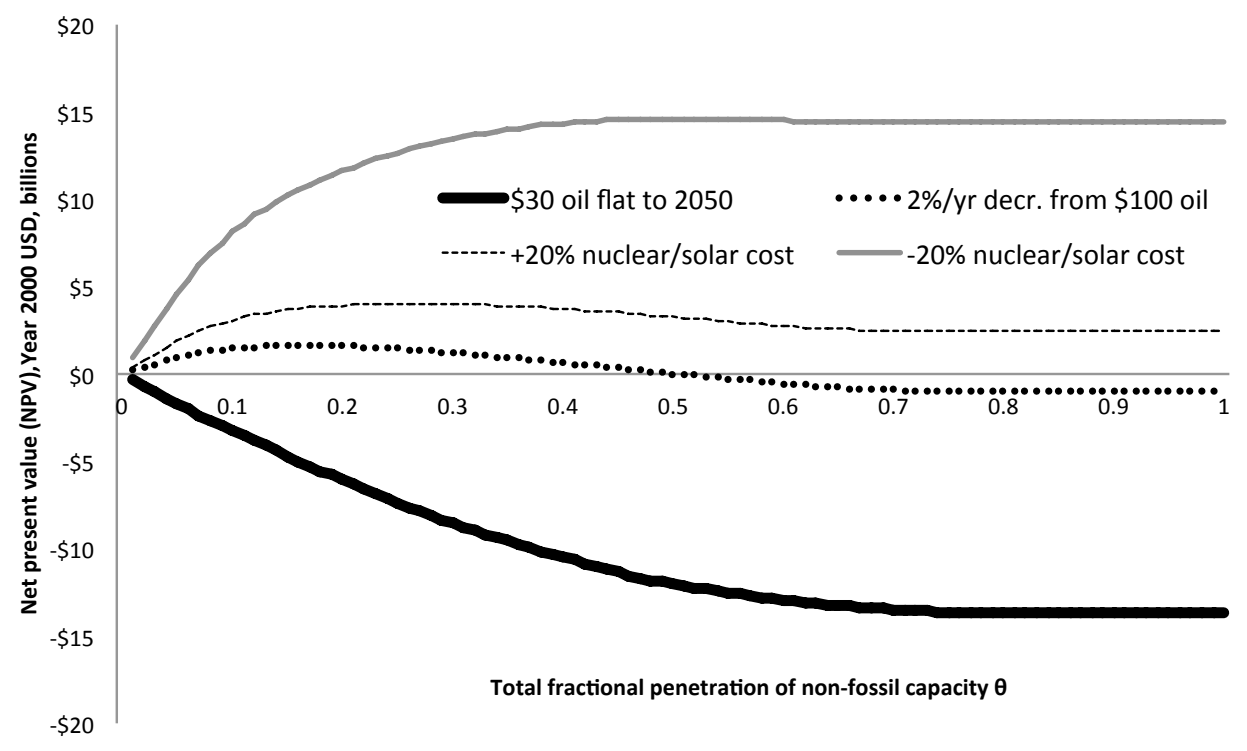

Figure 5: Net present value (NPV) curves for the COST case in Saudi Arabia. Under the COST case, oil prices and nuclear and solar investment costs are higher/lower than their BASE case values.

Figure 6 shows the NPV curves for the four scenarios of the ECON case. For the lower value of $\tau$ (more oil-dependent economy), the curve is shifted upward. The reason is that each barrel of oil displaced from the electricity system is more valuable when exported instead, since non-oil GDP growth is more tightly linked to oil sales. Conversely, under the higher value of $\tau$ (less oil-dependent economy), the net benefits of non-fossil capacity are fewer. $\mathrm{A}+/-50 \%$ change to the non-oil GDP growth rate $\gamma$ leads to a comparatively wider spread in NPV outcomes across the range of $\theta$. Larger (smaller) independent non-oil GDP growth rates lead to more (less) produced capital accumulation, shifting the NPV curve upward (downward). In all four scenarios of the ECON case, the NPV $>0$ across the range of $\theta$. 


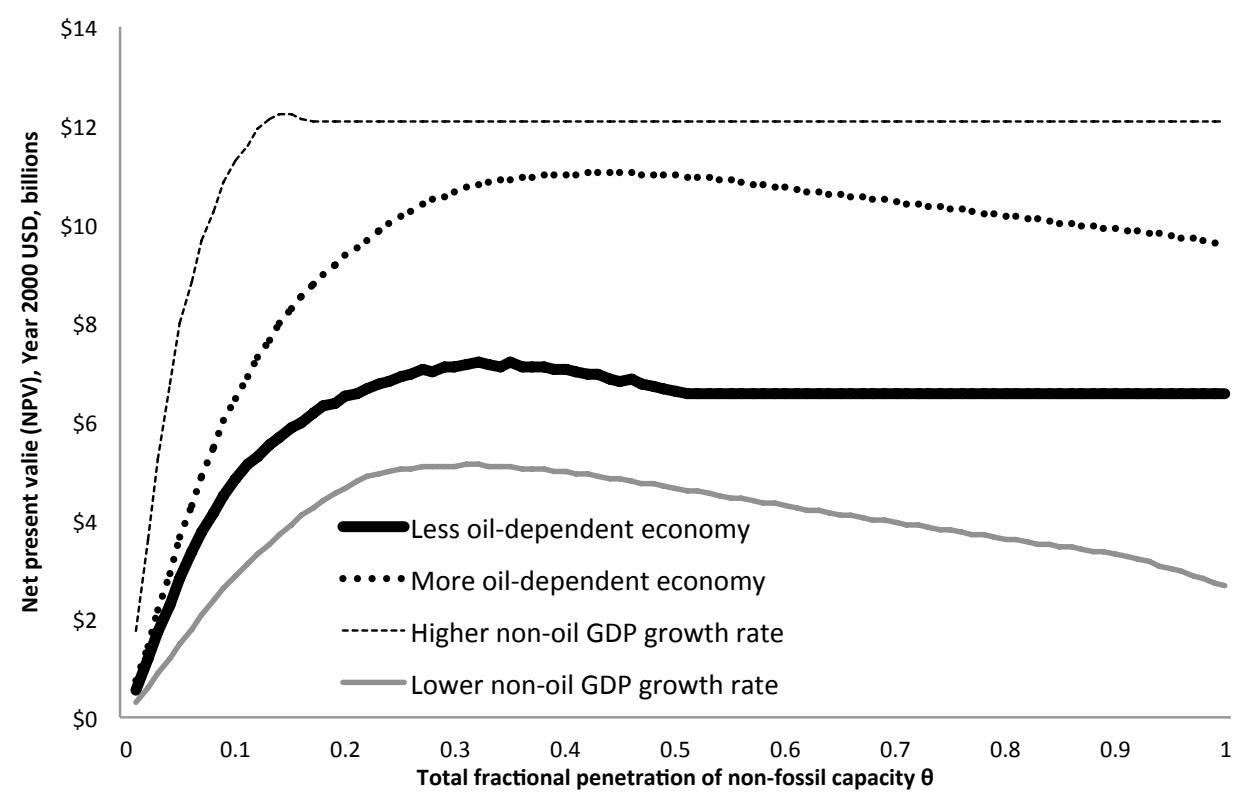

Figure 6: Net present value (NPV) curves for the ECON case in Saudi Arabia. Under the ECON case, $\tau$ and $\gamma$ are $+/-50 \%$ of their BASE case values.

The policy evaluation results for Saudi Arabia indicate that investment in non-fossil generation capacity meets the sustainability acceptance criteria (produced capital benefits exceed oil capital costs) across a range of technology allocations and economic conditions. The actual NPV depends on the penetration $\theta$ and specific allocation to nuclear $\left(f_{N}\right)$ versus solar $\left(f_{S}\right)$. However under the lower oil price scenarios, oil capital costs can exceed produced capital benefits, resulting in negative NPVs that therefore do not meet the acceptance criteria. This analysis underscores that expectations about the future can produce a wide range of inclusive wealth impacts from the same set of non-fossil electricity policies.

\subsection{Comparison with Other Oil-Exporting Countries}

In this section, we compare the BASE case policy evaluation results for the Kingdom of Saudi Arabia (KSA) with two other oil-exporting countries, the United Arab Emirates (UAE) and Kuwait. 
Figure 7a shows the NPV curves for the three countries across the range of non-fossil penetration $\theta$. Benefits include only produced capital accumulation. Across the entire range of $\theta$, $\mathrm{NPV}<0$ for the UAE. This is because the majority of the UAE electricity system is already fueled by natural gas instead of oil, meaning non-fossil capacity will be displacing relatively less oil in the UAE system. While there are likely to be produced capital benefits to displacing natural gas consumption in the UAE, the opportunity cost of oil consumption is still significantly higher than natural gas, since oil is still the country's largest export and revenue source (see Table 1).

Kuwait, on the other hand, receives gains from low to medium penetrations of non-fossil capacity, since its electricity system is majority oil-fired. At higher penetrations, the costs of new power plants (particularly nuclear) rise steadily while the benefits begin to plateau, causing NPV to decline to nearly zero over the remaining range of $\theta$. This is because the Kuwaiti system is relatively small to begin with, making it costly to absorb large alternative capacity additions when conventional power plants are not forced to retire (thus continuing to incur yearly fixed costs).
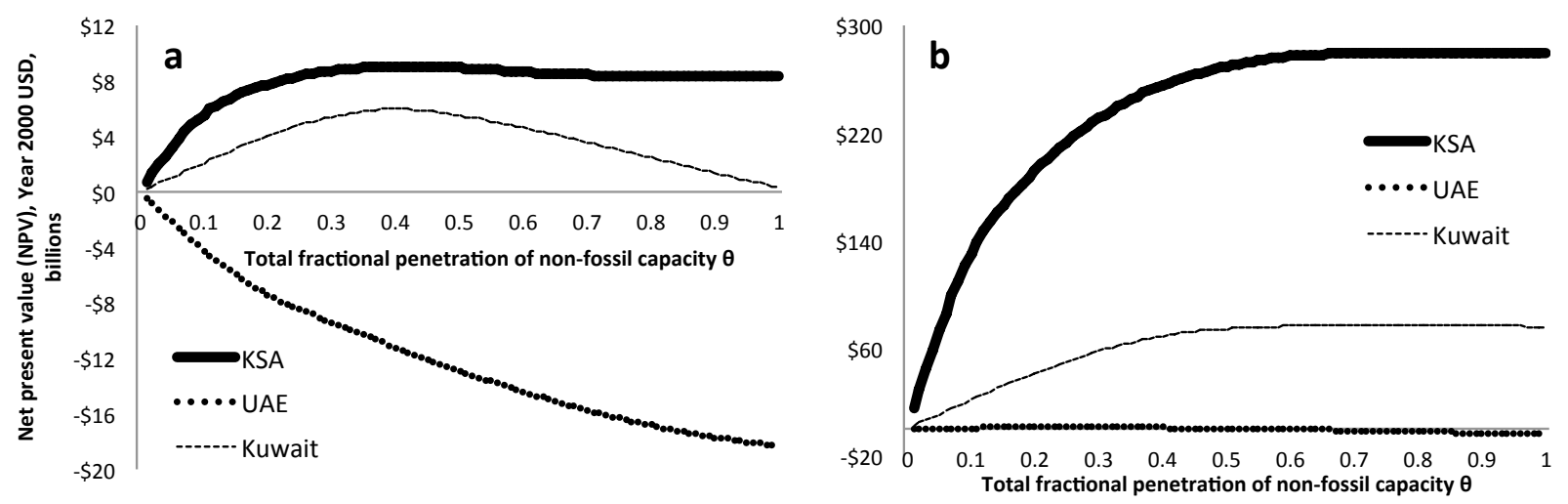

Figure 7a: Net present value (NPV) curves for the BASE case in KSA, UAE and Kuwait. Figure 7b: NPV curves for the BASE case in the countries, including human capital benefits. Figures are in Year 2000 US\$. Under the BASE case, nuclear and solar are equally allocated $\left(f_{N}=f_{S}=0.5\right)$. 


\subsection{Policy Evaluation Including Human Capital}

Figure $7 \mathrm{~b}$ shows the NPV curves for the three countries when human capital is included in the PV calculation. Saudi Arabia, because of its large and increasingly educated adult population, benefits the most from human capital gains (NPV increases by an order of magnitude across the range of $\theta$ ). The benefits are significant in Kuwait as well, raising the NPV curve substantially, but by comparison to KSA the Kuwaiti population is smaller and less educated (based on historical educational attainment extrapolations) over the course of the simulation. Thus, the marginal human capital gain from a unit wage increase is smaller. As above, the UAE still benefits least from non-fossil electricity policy. However, the NPV curve is now greater than zero until $\theta=0.55$, after which it is less than zero.

The results of the policy evaluation and scenario analysis show that different oilexporting countries experience a wide range of inclusive wealth benefits and costs when investing in non-fossil electricity infrastructures. Saudi Arabia and Kuwait show net increases to inclusive wealth across a range of policies. The UAE experiences net increase to inclusive wealth only if human capital benefits are included in the evaluation.

\section{Discussion}

We explored the application of inclusive wealth theory to prospective policy evaluation with dynamic simulation modeling, using the case of electricity infrastructure policies in oil-exporting countries. To demonstrate the prospective evaluation, we analyzed investment policies for nonfossil electricity capacity in these countries in terms of their forecast implications to inclusive wealth, as measured by the particular dimensions of inclusive wealth that we include. The purpose of the study is not to prescribe specific policies, but instead provide insights into how 
electricity policy in these countries affects the sustainability of development vis-à-vis changes to inclusive wealth. To scope the model we made necessary simplifications to how the capital assets are measured and impacted. In this section, we discuss the implications of our treatments of the capital assets and review areas for future research that can build on the work we have started.

While oil capital represents $80 \%$ of natural wealth in Saudi Arabia and $99 \%$ in the UAE and Kuwait (UNU-IHDP \& UNEP, 2014), non-fossil electricity policy in these countries will nonetheless impact other natural capital assets like water, air, and global climate, which we do not capture. However, from a more general sustainability perspective, even a sole focus on oil capital reveals important tradeoffs in the way society manages its natural capital. This is because civilization depletes natural capital - whether it is oil, forests, or air quality - in order to meet socioeconomic needs. Moving forward, what matters is how the rents of depleted assets - like oil - are allocated in order to promote sustainable development. The model developed for this case makes explicit the tradeoff between consuming oil in a conventional electricity system and using oil rents to finance a non-fossil system, suggesting that the latter is more likely to promote sustainable development in oil-exporting countries. Similar tradeoffs are likely to exist in other natural resource-exporting countries. Furthermore, from a modeling standpoint, our treatment of oil capital shows that one could, in principle, incorporate any number of additional natural assets in more comprehensive assessments provided their dynamics can be appropriately specified.

In our analysis, policies alter the development of the electricity infrastructure, but infrastructure capital is actually a subset of produced capital. In the policy evaluation we assumed that one unit of electricity generated by a nuclear or solar power plant is valued equivalently to one unit generated at a conventional facility. In reality this is not the case, owing 
to differences in pollution and waste externalities across the technologies. For example, our analysis did not consider the local health benefits of non-fossil electricity systems by avoiding air pollution, a serious problem in Saudi Arabia and other oil-exporting countries of the Middle East (Mathers et al., 2008). We also did not model the costs associated with nuclear waste disposal and storage. A more detailed assessment of inclusive wealth impacts would estimate for each unit of electricity produced by the infrastructure asset both the benefits and the costs, measured in terms of the accumulations and depletions of other capital assets caused by the externalities.

In light of the recent precipitous drop in world oil prices, it is worth discussing further the implications of the oil price trajectory on the policy evaluation results. Our scenarios for the oil price trajectory out to 2050 are not meant to capture the cone of uncertainty in world oil price developments. They are meant to illustrate how different forecasts of the long-term oil price can affect the NPV of non-fossil investment policies, and as Figure 5 shows, low forecasts can lead to negative NPVs. The prospect of forecasting the oil price that far into the future, however, is clearly futile; it is also possible that prices climb beyond $\$ 100$ if geopolitical conditions shift, the oil supply surplus becomes a shortage, or a carbon price is instituted. This underscores that the purpose of our model is not to be predictive or prescriptive, but instead to demonstrate how the inclusive wealth framework could be applied to prospective policy analysis.

As we show in Section 3.3, human capital benefits can be a large part of the rationale for pursuing alternative policies over a BAU. This finding is consistent with the retrospective sustainability evaluations of Arrow et al. (2012) and UNU-IHDP \& UNEP $(2012,2014)$, who showed that changes in human capital dominated many of the countries' changes in inclusive wealth over time. Still, there remain fundamental difficulties in quantifying the contribution of human capital, from both conceptual and practical perspective. Our approximation makes 
assumptions about the ratio between wages and GDP, which may vary across countries. We also do not capture changing demographics, which would cause the fraction of adults in the population to change over time. Finally, while inclusive wealth theory states that capital stocks be valued at constant shadow prices in order to track intergenerational human well-being, in our evaluation the simulated real wage (and thus shadow price) dynamically adjusts to changing economic conditions. Thus while human capital grows as a result of electricity infrastructure decisions, its growth via increases to the shadow price may be severing the link from wealth to well-being, which is the ultimate quantity to be sustained. This underscores the importance of advancing theoretical as well as applied research in human capital measurement.

Due to the aforementioned simplifications we impose on the capital assets, it is worth discussing the difference between sustainability and optimality when evaluating policies. The policy acceptance criterion for sustainability is a net present value (NPV) greater than zero, since this indicates that the social value of capital accumulations caused by the policy exceeds the capital depletions. In theory, an optimal policy will maximize NPV, this at a point where marginal benefits (capital accumulations) equal marginal costs (capital depletions). In this paper we showed that multiple policies across a range of non-fossil penetrations $\theta$ promote sustainable development, but we did not calculate an optimal policy for any of the three countries. The main reason is because we are capturing only a subset of the capital assets that determine well-being, thus an "optimal" policy would be optimal only in our narrowly defined world of what promotes sustainable development (ignoring for example, social and knowledge capital, as well as externalities like pollution).

Applying inclusive wealth theory to prospective policy evaluation requires projecting capital stock trajectories into the future, which furthermore requires a dynamic simulation model 
that can capture interactions between the impacted capital stocks. There are multiple modeling approaches to dynamic simulation that could be used in inclusive wealth-based policy evaluation. Computable general equilibrium (CGE) models permit specification of multiple economic sectors, in particular their interdependencies (in contrast, our model was based on a simple two-sector economy). In oil-exporting countries, these sectors may be differentially dependent on the oil sector, which could lead to different impacts to GDP and therefore produced capital accumulation. CGE models also permit specification of a labor sector, which could be modified to measure human capital. Agent-based models (ABM) permit modeling interactions between heterogeneous population groups with different attributes and decision rules. In electricity infrastructure planning, to whom the benefits and costs accrue will depend on, for example, whether the electricity price increases, and how the increase is distributed across income groups in the population. Thus, an ABM approach could capture distributional impacts of policy interventions to per capita inclusive wealth in a way that our model could not. These approaches underscore that there are numerous potential extensions to the model that provide a more comprehensive representation of capital stock dynamics.

\subsection{Conclusions}

In this paper, we apply inclusive wealth theory to forward-looking policy evaluation for sustainable development. We evaluate prospective policies, where benefits and costs are measured in terms of the social value of forecast capital asset accumulations and depletions, respectively. This builds on prior work that has largely focused on retrospective accounting of capital stock trajectories and/or theoretical extensions. The case study involves electricity infrastructure planning in oil-exporting countries. To make projections of, and measure the impacts to, select capital stocks that comprise inclusive wealth, we develop a dynamic simulation 
model of salient energy-economy interactions in oil-exporting countries. Illustrative results show that investing in capacity for non-fossil electricity production in Saudi Arabia and Kuwait can produce a net increase to the countries' inclusive wealth, though the impacts depend on future uncertainties. In contrast, the UAE's net inclusive wealth declines under similar investment policies. Expanding the approximation of benefits to include human capital improvements can substantially increase net inclusive wealth, though calculated benefits vary across countries due to differences in projected educational attainment. While the case is simplified in numerous ways, the findings nonetheless demonstrate the feasibility of applying inclusive wealth theory to conduct prospective policy analysis and garner insight into what makes sustainable development more or less likely.

\section{Acknowledgements}

The Center for Complex Engineering Systems (CCES) at KACST (King Abdulaziz City for Science and Technology) and MIT funded this research under a collaborative agreement signed on July 1, 2011. Ross Collins acknowledges additional funding from a National Science Foundation Graduate Research Fellowship and a Martin Family Society for Sustainability Fellowship. This work was also partially conducted while Ross Collins was a Fellow in the Sustainability Science Program at Harvard University. Support for that Program from Italy's Ministry for Environment, Land and Sea is therefore gratefully acknowledged. The funding sources had no direct involvement in the preparation of the article. Finally, the authors would like to thank the numerous contributors from Harvard, MIT and CCES who devoted their time and energy to this work, in particular Kenneth Strzepek, Stephen Connors, Adnan Alsaati, and Anas Alfaris. 


\section{Appendix A. Capacity Expansion Equations}

This appendix further describes how electric power capacity expansion is modeled. The desired conventional capacity $(D C)$ is based on a forecast of peak load $(P L)$. The electricity system will expand to meet forecasted peak load $(F P L)$ over a particular time horizon $h$, which is five years. FPL assumes $P L$ will grow according to a linear extrapolation $T$ of its past behavior. Electricity demand $E$ is converted to peak load through a load factor $(L F)$, which is the ratio of average demand to maximum demand in a given time period, in this case a year. In Saudi Arabia, $L F$ averaged roughly 0.6 between 2006 and 2011 (ECRA, 2012a; SEC, 2013). Lacking the necessary data for UAE and Kuwait, we assume the same value.

$$
\begin{gathered}
F P L=P L(1+T h) \\
P L=\frac{E}{L F * 8760}
\end{gathered}
$$

$D C$ expands to meet forecasted peak load $(F P L)$ plus a planning reserve margin $(m)$, which is $20 \%$. The start rate $(S R)$ for new capacity is either the desired start rate $(D S R)$ or zero. $D S R$ is the sum of the desired online rate $(D O R)$ and the adjustment for capacity under construction, which is the difference between desired capacity under construction (DCUC) and the current capacity under construction $(C U C)$ divided by an adjustment time $\left(\tau_{u}\right)$. DCUC is determined, following Little's Law, by the product of DOR and the technology-specific construction delay $\left(\tau_{d}\right)$ (see Table 2). DOR, if positive, is the sum of the discard rate $(D R)$ of old plants and the adjustment for capacity, which is the difference between desired capacity $(D C)$ and current capacity $(C)$ divided by an adjustment time $\left(\tau_{c}\right)$. The adjustment times, $\tau_{u}$ and $\tau_{c}$, 
dictate how fast the capacity expansion process responds to changes in forecasted demand (mathematically, a first-order exponential smoothing function of the discrepancy between desired and current capacity). They were estimated using a maximum likelihood algorithm with historical conventional capacity data from Saudi Arabia (ECRA, 2012b; SEC, 2013). Their values are 10.0 years and 5.5 years, respectively (again, lacking the necessary data for UAE and Kuwait, we assume the same values). Finally, the actual online rate $(O R)$ is the ratio of $C U C$ to $\tau_{d}$, and the discard rate $(D R)$ is the ratio of $C$ to average power plant lifetime $n$.

$$
\begin{gathered}
D C=F P L(1+m) \\
S R=\operatorname{Max}(0, D S R) \\
D S R=D O R+\left(\frac{D C U C-C U C}{\tau_{u}}\right) \\
D C U C=D O R * \tau_{d} \\
D O R=\operatorname{Max}\left(0, D R+\left(\frac{D C-C}{\tau_{c}}\right)\right) \\
O R=\frac{C U C}{\tau_{d}} \\
D R=\frac{C}{n}
\end{gathered}
$$

Desired alternative capacity $(D A C)$ captures the desire of a policy to meet a forecast of peak load $\left(F P L_{A}\right)$ by the simulation terminal year $y$ with some penetration of non-fossil power capacity $\theta(0 \leq \theta \leq 1)$. As the simulation progresses, the time horizon of the forecast will decrease such that actual non-fossil capacity converges to the target penetration level by $y$. 
Conventional capacity is used exclusively to cover the reserve margin. Within $D A C$, the desired amounts of nuclear capacity $(D N C)$ and solar PV capacity $(D S C)$ are determined by fractional allocations $f_{N}$ and $f_{S}$, respectively, where $f_{N}+f_{S}=1$.

$$
\begin{gathered}
D A C(t)=\theta F P L_{A}(y-t) \\
F P L_{A}(y-t)=P L(1+T(y-t)) \\
D N C(t)=f_{N}(t) D A C(t) \\
D S C(t)=f_{S}(t) D A C(t)
\end{gathered}
$$

To prevent overbuilding of capacity, the control logic for the conventional capacity pipeline needs to be amended to account for non-fossil capacity expansion. Specifically, Eqs. A.5 and A.7 now need to account for the amount of nuclear and solar capacity online $\left(C_{N}\right.$ and $\left.C_{S}\right)$ and under construction $\left(C U C_{N}\right.$ and $\left.C U C_{S}\right)$, shown below. Thus, the conventional capacity expansion process dynamically adjusts according to the policy changes made to the nuclear and solar systems.

$$
D S R=D O R+\left(\frac{D C U C-C U C-C U C_{N}-C U C_{S}}{\tau_{u}}\right)
$$




$$
D O R=\operatorname{Max}\left(0, D R+\left(\frac{D C-C-C_{N}-C_{S}}{\tau_{c}}\right)\right)
$$

The structure of the capacity expansion process for nuclear and solar energy is identical to that of conventional capacity, except for two key differences. One, there is a start rate limit $(S R L)$ imposed on nuclear and solar capacity entering the construction pipeline. If not for the limit, an unrealistic amount of capacity would immediately enter the pipeline, particularly for the high penetration policies. Thus, the limit is set at $2 \mathrm{GW}$ per year for each technology, roughly equivalent to one large nuclear power plant or solar farm per year. The $S R L$ is the reason why the BCR and NPV curves flatten out at higher penetrations in many of the figures. In other words, the electricity systems desire more capacity than the limit allows to be built, resulting in the same amount of non-fossil capacity even as $\theta$ increases. The equations for the nuclear start rate (NSR) and solar start rate (SSR) are shown below.

Two, while conventional capacity is assumed to come online in a modular fashion (specifically, according to a first-order exponential delay; see Eq. A.8), non-fossil capacity additions are likely to be much "lumpier", particularly for nuclear power. This is because none of the countries analyzed in this paper currently have a nuclear or solar installed base on which to make modular additions. Thus, we formulate the construction delay $\tau_{d}$ for nuclear as a fixed delay (also called a "pipeline delay"), whereby the amount of capacity that enters construction in year $t$ will exactly come online in year $t+\tau_{d}$. For solar, we formulate the construction delay as a high-order exponential delay, but not fixed per se. Thus, small amounts of solar capacity that enter the pipeline in year $t$ can actually come online before year $t+\tau_{d}$. For solar photovoltaic (PV) this is an appropriate assumption, since a utility-scale PV farm can start generating electricity before all of the planned panels have been installed. 


$$
\begin{aligned}
& N S R=\operatorname{Min}\left(S R L_{N}, \operatorname{Max}\left(0, D S R_{N}\right)\right) \\
& S S R=\operatorname{Min}\left(S R L_{S}, \operatorname{Max}\left(0, D S R_{S}\right)\right)
\end{aligned}
$$




\section{References}

Alsweilem, K. (2015). A Stable and Efficient Fiscal Framework for Saudi Arabia: The Role of Sovereign Funds in Decoupling Spending from Oil Revenue and Creating a Permanent Source of Income. Belfer Center for Science and International Affairs and Center for International Development: Harvard Kennedy School.

Arrow, K. J., Dasgupta, P., Goulder, L. H., Mumford, K. J., \& Oleson, K. (2012). Sustainability and the Measurement of Wealth. Environment and Development Economics, 17, 317-353.

Arrow, K. J., Dasgupta, P., \& Mäler, K.-G. (2003). Evaluating projects and assessing sustainable development in imperfect economies. Environmental and Resource Economics, 26(4), 647-685.

Barro, R. J., \& Lee, J. W. (2013). A new data set of educational attainment in the world, 1950-2010. Journal of Development Economics, 104, 184-198.

Barro, R. J., \& Sala-i-Martin, X. (2003). Economic Growth (2nd Edition). MIT Press.

BEA. (2015). National Income and Product Accounts Tables. US Bureau of Economic Analysis. Retrieved from http://www.bea.gov/iTable/iTable.cfm?ReqID=9\&step=1\#reqid=9\&step=1\&isuri= 1

Bianco, V., Manca, O., \& Nardini, S. (2009). Electricity consumption forecasting in Italy using linear regression models. Energy, 34(9), 1413-1421.

BMI. (2014). Saudi Arabia Oil \& Gas Report: Includes 10-Year Forecasts to 2023 (No. ISSN 1748-4219). London, UK: Business Monitor International. 
BMI. (2015a). Industry Forecast - Upstream Production - Oil - Kuwait - Q2 2015. Business Monitor International. Retrieved from https://bmo.bmiresearch.com/article/view?article=1043275\&advanced_search=1 \&keyword=Kuwait

BMI. (2015b). Industry Forecast - Upstream Production - Oil - United Arab Emirates - Q2 2015. Business Monitor International. Retrieved from https://bmo.bmiresearch.com/article/view?article=1043063\&advanced_search=1 \&keyword=United\%20arab\%20emirates

Collins, R. D. (2015). Using inclusive wealth as a measure of sustainability for infrastructure planning and evaluation (PhD Dissertation). Massachusetts Institute of Technology, Institute for Data, Systems, and Society.

Collins, R. D., Gowharji, W., Habib, A., Alwajeeh, R., Connors, S. R., \& Alfaris, A. (2013). Evaluating scenarios of capacity expansion given high seasonal variability of electricity demand: the case of Saudi Arabia. Presented at the 31st International Conference of the System Dynamics Society, Cambridge, MA, USA.

Collins, R., Sakhrani, V., Selin, N., Alsaati, A., \& Strzepek, K. (2014). Using inclusive wealth for policy evaluation: the case of infrastructure capital. In Inclusive Wealth Report 2014: Measuring Progress toward Sustainability. Cambridge, UK: Cambridge University Press.

Dasgupta, P. (2001). Human well-being and the natural environment. OUP Catalogue. Retrieved from https://ideas.repec.org/b/oxp/obooks/9780199247882.html Dasgupta, P. (2009). The welfare economic theory of green national accounts. Environmental and Resource Economics, 42(1), 3-38. 
Dasgupta, P. (2014). Measuring the Wealth of Nations. Annual Review of Resource Economics, (0). Retrieved from http://www.annualreviews.org/doi/abs/10.1146/annurev-resource-100913012358

Dasgupta, P., \& Duraiappah, A. (2012). Well-being and wealth. In Inclusive Wealth Report 2012: Measuring Progress toward Sustainability. Cambridge, UK: Cambridge University Press.

Dyner, I., \& Larsen, E. R. (2001). From planning to strategy in the electricity industry. Energy Policy, 29(13), 1145-1154.

ECRA. (2006). Updated Generation Planning for the Saudi Electricity Sector. Riyadh, Saudi Arabia: Electricity \& Cogeneration Regulatory Authority of Saudi Arabia. Retrieved from http://www.ecra.gov.sa/pdf/longtermgenerationplanningforsaudielectricitysectors tudy.pdf

ECRA. (2012a). Activities \& Achievements of the Authority in 2011. Riyadh, Saudi Arabia: Electricity \& Cogeneration Regulatory Authority of Saudi Arabia.

ECRA. (2012b). Power plant data by region. Electricity \& Cogeneration Regulatory Authority of Saudi Arabia.

EIA. (2014a). Electricity Market Module - Assumptions to the Annual Energy Outlook (No. DOE/EIA-M068(2014)). Energy Information Administration. Retrieved from http://www.eia.gov/forecasts/aeo/assumptions/pdf/electricity.pdf

EIA. (2014b). International energy data and analysis. US Energy Information Administration. Retrieved from http://www.eia.gov/beta/international/ 
Ford, A. (1997). System dynamics and the electric power industry. System Dynamics Review, 13(1), 57-85.

Ford, A. (2002). Boom and bust in power plant construction: lessons from the California electricity crisis. Journal of Industry, Competition and Trade, 2(1-2), 59-74.

Gowharji, W., Habib, A., Collins, R. D., Al Wajeeh, R., AlAbdulkareem, A., Alfaris, A., \& Connors, S. R. (2014). A multi-attribute decision support framework for conventional generation capacity expansion (pp. 227-234). Presented at the Systems Conference (SysCon), 2014 8th Annual IEEE, Vancouver, Canada: IEEE. Retrieved from http://ieeexplore.ieee.org/xpls/abs_all.jsp?arnumber=6819262 Hamilton, K., \& Clemens, M. (1999). Genuine savings rates in developing countries. The World Bank Economic Review, 13(2), 333-356.

Hicks, J. R. (1940). The valuation of the social income. Economica, 105-124.

IEA. (2014). Energy Balances of Non-OECD Countries (Statistics Publication and CD-ROMs No. ISBN 978-92-64-21708-9). Paris, France: International Energy Agency.

Kypreos, S., Krakowski, R., Röder, A., Wei, Z., \& Chen, W. (2003). Energy economy modeling scenarios for China and Shandong. In Integrated Assessment of Sustainable Energy Systems in China. Kluwer Academic Publishers.

Lahn, G., Stevens, P., \& Preston, F. (2013). Saving Oil and Gas in the Gulf. Chatham House. Retrieved from http://www.chathamhouse.org/publications/papers/view/193884\# Lindahl, E. (1933). The concept of income. In Economic essays in honour of Gustav Cassel. London, UK: Allen \& Unwin. 
Lindmark, M., \& Acar, S. (2013). Sustainability in the making? A historical estimate of Swedish sustainable and unsustainable development 1850-2000. Ecological Economics, 86, 176-187.

Mathers, C., Fat, D. M., \& Boerma, J. T. (2008). The global burden of disease: 2004 update. Geneva, Switzerland: World Health Organization.

Meadows, D. H. (1998). Indicators and information systems for sustainable development. Hartland Four Corners, VT: The Sustainability Institute. Retrieved from http://www.comitatoscientifico.org/temi\%20SD/documents/@@Meadows\%20SD \%20indicators.pdf

Moe, T., Alfsen, K. H., \& Greaker, M. (2013). Sustaining Welfare for Future Generations: A Review Note on the Capital Approach to the Measurement of Sustainable Development. Challenges in Sustainability, 1(1), 16-26.

Mohamed, Z., \& Bodger, P. (2005). Forecasting electricity consumption in New Zealand using economic and demographic variables. Energy, 30(10), 1833-1843.

Mota, R. P., Domingos, T., \& Martins, V. (2010). Analysis of genuine saving and potential green net national income: Portugal, 1990-2005. Ecological Economics, 69(10), 1934-1942.

Muñoz, P. (2013). Overview on IWR 2012: Methods and datasets. Paris, France. Ollivier, T., \& Giraud, P.-N. (2011). Assessing sustainability, a comprehensive wealth accounting prospect: An application to Mozambique. Ecological Economics, 70(3), 503-512. 
Pearce, D. W., \& Atkinson, G. D. (1993). Capital theory and the measurement of sustainable development: an indicator of "weak" sustainability. Ecological Economics, 8(2), 103-108.

Pearson, L. J., Biggs, R., Harris, M., \& Walker, B. (2013). Measuring sustainable development: the promise and difficulties of implementing Inclusive Wealth in the GoulburnBroken Catchment, Australia. Sustainability Social Science at the Applied Science and Engineering Universities, 9(1), 16.

Pierru, A., \& Matar, W. (2012). The impact of oil price volatility on welfare in the Kingdom of Saudi Arabia: implications for public investment decision-making. Retrieved from http://papers.ssrn.com/sol3/papers.cfm?abstract_id=2110172

Polasky, S., Bryant, B., Hawthorne, P., Johnson, J., Keeler, B., \& Pennington, D. (2015). Inclusive Wealth as a Metric of Sustainable Development. Annual Review of Environment and Resources, 40(1). Retrieved from http://www.annualreviews.org/doi/abs/10.1146/annurev-environ-101813013253

SAMA. (2013). SAMA National Account Statistics. Saudi Arabian Monetary Agency. Retrieved from http://www.sama.gov.sa/sites/samaen/ReportsStatistics/Pages/AnnualReport.asp $\mathrm{x}$

Sato, M., Samreth, S., \& Yamada, K. (2012). A numerical study on assessing sustainable development with future genuine savings simulation. International Journal of Sustainable Development, 15(4), 293-312. 
SDSN. (2014). An Action Agenda for Sustainable Development: Report for the UN SecretaryGeneral. Sustainable Development Solutions Network. Retrieved from http://unsdsn.org/wp-content/uploads/2013/06/140505-An-Action-Agenda-forSustainable-Development.pdf

SEC. (2013). Annual Report 2012. Riyadh, Saudi Arabia: Saudi Electricity Company. Sterman, J. D. (2000). Business dynamics: systems thinking and modeling for a complex world (Vol. 53). Irwin McGraw-Hill.

TCB. (2013). Total Economy Database (TED). The Conference Board. Retrieved from https://www.conference-board.org/data/economydatabase/

Tidball, R., Bluestein, J., Rodriguez, N., \& Knoke, S. (2010). Cost and performance assumptions for modeling electricity generation technologies (Contract No. 303) (pp. 275-3000). National Renewable Energy Laboratory. Retrieved from http://www.nrel.gov/docs/fy11osti/48595.pdf

Tokimatsu, K., Yamaguchi, R., Sato, M., Yasuoka, R., Nishio, M., \& Ueta, K. (2011). Measuring future dynamics of genuine saving with changes of population and technology: application of an integrated assessment model. Environment, Development and Sustainability, 13(4), 703-725.

Tokimatsu, K., Yamguchi, R., Sato, M., Yasuoka, R., Nishio, M., \& Ueta, K. (2013). Assessing future sustainability by forecast of Genuine Savings paths. Environmental Economics and Policy Studies, 1-21.

UNDESA. (2014). World Population Prospects: The 2012 Revision. United Nations, Department of Economic and Social Affairs: Population Division, Population Estimates and Projections Section. Retrieved from http://esa.un.org/wpp/ 
UNSD. (2013). National Accounts Main Aggregates Database. United Nations Statistics Division. Retrieved from http://unstats.un.org/unsd/snaama/dnllist.asp UNU-IHDP, \& UNEP. (2012). Inclusive Wealth Report 2012: Measuring Progress toward Sustainability. Cambridge, UK: Cambridge University Press.

UNU-IHDP, \& UNEP. (2014). Inclusive Wealth Report 2014: Measuring Progress toward Sustainability. Cambridge, UK: Cambridge University Press.

World Bank. (2006). Where is the wealth of nations? Washington DC: World Bank. World Bank. (2011). The changing wealth of nations. Washington DC: World Bank. World Bank. (2014). World DataBank: World Development Indicators. Retrieved from http://databank.worldbank.org/data/views/variableSelection/selectvariables.aspx ?source=world-development-indicators

World Commission on Environment and Development. (1987). Our Common Future. Oxford: Oxford University Press.

WTO. (2015). Time Series - Merchandise trade by commodity. World Trade Organization. Retrieved from http://stat.wto.org/StatisticalProgram/WSDBStatProgramHome.aspx?Language=E 